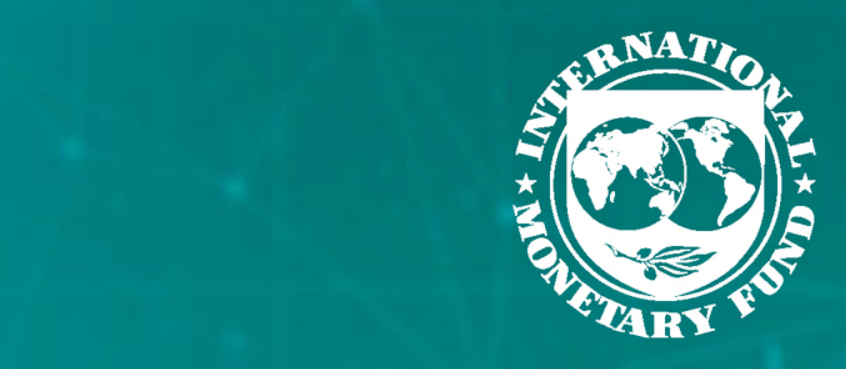

\title{
NOTES
}

\section{DISTRIBUTED LEDGER TECHNOLOGY EXPERIMENTS IN PAYMENTS AND SETTLEMENTS}

Ghiath Shabsigh, Tanai Khiaonarong, Harry Leinonen 


\section{FINTECH NOTE}

\section{Distributed Ledger Technology Experiments in Payments and Settlements}

Prepared by Ghiath Shabsigh, Tanai Khiaonarong, and Harry Leinonen (IMF Consultant) June 2020

$\begin{array}{lllllllllllllllllllllllll}\text { I } & N & T & E & R & N & A & T & \text { I } & \text { O } & N & \text { A } & L & M & O & \text { N } & \text { E } & T & A & R & Y & F & \text { U } & N & D\end{array}$ 


\section{(C)2020 International Monetary Fund \\ Cover Design: IMF Multimedia Services \\ Composition: The Grauel Group}

Names: Shabsigh, Ghiath. | Tanai Khiaonarong. | Leinonen, Harry. | International Monetary Fund, publisher.

Title: Distributed ledger technology experiments in payments and settlements / Prepared by Ghiath Shabsigh, Tanai Khiaonarong, and Harry Leinonen (IMF Consultant).

Other titles: FinTech notes (International Monetary Fund).

Description: Washington, DC : International Monetary Fund, 2020. | FinTech notes. | June 2020. Includes bibliographical references.

Identifiers: ISBN 9781513536330 (paper) | 9781513536354 (web pdf)

Subjects: LCSH: Blockchains (Databases). | Financial services industry-Technological innovations. | Electronic funds transfers.

Classification: LCC QA76.9.B56 S53 2020

DISCLAIMER: Fintech Notes offer practical advice from IMF staff members to policymakers on important issues. The views expressed in Fintech Notes are those of the author(s) and do not necessarily represent the views of the IMF, its Executive Board, or IMF management.

Publication orders may be placed online, by fax, or through the mail:

International Monetary Fund, Publication Services

PO Box 92780, Washington, DC 20090, U.S.A.

Tel.: (202) 623-7430 Fax: (202) 623-7201

Email: publications@imf.org

www.imf bookstore.org 
Abbreviations $\quad \underline{\mathbf{v}}$

Executive Summary vii

Introduction $\quad \underline{1}$

Distributed Ledger Technology

Experiments and Research $\underline{\underline{2}}$

Risk Management Issues $\quad \underline{5}$

Financial Market Infrastructure Standards $\quad \underline{Z}$

Potential Impact on the International Monetary System $\quad \underline{8}$

Conclusion $\quad \underline{8}$

Annex I. List of DLT Experiments and Research in Payments and Settlements $\quad \underline{10}$

Annex II. Distributed Ledger Technology Protocols $\quad \underline{11}$

References $\quad \underline{12}$ 
This page intentionally left blank 


$\begin{array}{ll}\text { BOC } & \text { Bank of Canada } \\ \text { CBDC } & \text { central bank digital currency } \\ \text { CCP } & \text { central counterparty } \\ \text { CLS } & \text { CLS Bank International } \\ \text { CPMI } & \text { Committee on Payments and Market Infrastructures } \\ \text { CPSS } & \text { Committee on Payment and Settlement Systems } \\ \text { CSD } & \text { central securities depository } \\ \text { DLT } & \text { distributed ledger technology } \\ \text { DVP } & \text { delivery versus payment } \\ \text { FMI } & \text { financial market infrastructure } \\ \text { GPI } & \text { Global Payments Innovation } \\ \text { IOSCO } & \text { International Organization of Securities Commissions } \\ \text { LSM } & \text { liquidity saving mechanism } \\ \text { LVPS } & \text { large-value payment system } \\ \text { MAS } & \text { Monetary Authority of Singapore } \\ \text { PFMI } & \text { Principles for Financial Market Infrastructures } \\ \text { PKI } & \text { public key infrastructure } \\ \text { RTGS } & \text { real-time gross settlement } \\ \text { SWIFT } & \text { Society for Worldwide Interbank Financial Telecommunication } \\ \text { USC } & \text { Utility Settlement Coin }\end{array}$


This page intentionally left blank 
The last decade was a wake-up call for the financial sector with many explorations made into the use of distributed ledger technology (DLT) for payments and settlements. ${ }^{1}$ DLT has triggered a wave of innovations, experiments, research, and analysis of policy issues. Many lessons can be drawn from these projects to help inform policymakers and the industry on DLT's potential benefits and risks, which could have implications on international standards for financial infrastructures to ensure safety and efficiency in the public's interest.

So far, experiments with DLT point to the potential for financial infrastructures to move toward real-time settlement, flatter structures, continuous operations, and global reach. Testing in large-value payments and securities settlement systems has partly demonstrated the technical feasibility of DLT for this new environment. The projects analyzed issues associated with operational capacity, resiliency, liquidity savings, settlement finality, and privacy. DLT-based solutions can also facilitate delivery versus payment of securities, payment versus payment of foreign exchange transactions, and efficient cross-border payments.

The analysis points to key issues that could require further attention. Most experiments have been completed under controlled and technology-focused environments. All reviewed projects concluded that DLT is, at least to some extent, feasible as the basis for a large-value payment system (LVPS) infrastructure, but there were some views warning against this technology's immaturity and lack of interoperability. Very few projects have explicitly and rigorously assessed risks against international standards for large-value payments and securities settlement systems. Almost none of the projects involved a cost-benefit analysis, and no conclusions could be reached on whether DLT-based or improved legacy systems could be the more efficient alternative in the future. Liquidity, credit, transaction delay, settlement finality, counterparty, and operational risks could also change in varying degrees in a new environment.

Key issues include major changes to the current payments, clearing, and settlements arrangements, which could have a strong impact on users, participants, and markets. The evolution toward new infrastructures would require stakeholder consultations, a review of system rules, market conventions, transaction reconciliation practices for synchronized distributed ledgers, and an analysis of the impact on continuous operations (based on 24/7/365). Second, further work would benefit from a more explicit and rigorous analysis of potential risks against the international standards for financial market infrastructures and against the analytical framework for DLT introduction in payment, clearing, and settlement. Further, international standards may warrant new interpretations with respect to the evolving new types of risks. Third, investment and operational costs would need to be determined and included in a transparent cost-recovery pricing policy as part of any cost-benefit analysis before actual implementation. And fourth, interoperability issues would need to be addressed to avoid fragmentation risk. 
This page intentionally left blank 


\section{Introduction}

Major transformations in payments and settlements have occurred in generations. The first generation was paper-based. Delivery times for payment instruments took several days domestically and weeks internationally. The second generation involved computerization with batch processing. Links between payment systems were made through manual or file-based interfaces. The changeover period between technologies was long. Some paper-based instruments like checks and cash remain in use. The third generation, which has been emerging, involves electronic and mobile payment programs that enable integrated, immediate, and end-to-end payment and settlement transfers. For example, real-time gross settlement (RTGS) systems have been available in almost all countries. Distributed ledger technology (DLT) has been viewed as a potential platform for the next generation of payment systems, enhancing the integration and the reconciliation of settlement accounts and their ledgers. This is in addition to other technological developments (Box 1).

Research in using DLT for payments and settlements has provided insights on their potential benefits, risks, limitations, and implementation challenges. Large-value interbank payment projects have been completed in Brazil, Canada, the Euro Area/Japan, Singapore, South Africa, and Thailand. Securities settlement projects have been investigated in Australia, Canada, the Euro Area/Japan, Germany, Singapore, and the United States. Central banks and the private sector have also analyzed the improvement of cross-border payments through DLT.

This note takes stock of DLT experiments and research in payments and settlement systems. ${ }^{1}$ DLT and its protocols are described, and the experiments and research projects are summarized. Emerging risk management issues, implications for international standards, and potential implications for the international monetary system are discussed. The note aims to pro-

\footnotetext{
${ }^{1}$ Annex I includes a list of the experiments and research projects. The stock-taking exercise is based on the availability of public information. Retail payment applications are not in the scope of this note.
}

vide a balanced view with considerations for practical implementation and probable long-term applications and benefits for payment system developments.

\section{Distributed Ledger Technology}

DLT enables entities to carry out transactions in payment and settlement systems without necessarily relying on a central authority to maintain a single ledger. ${ }^{2}$ DLT networks could be open or closed (permissioned) depending on their participation policies. Various DLT protocols have been used so far in experiments in payments and securities settlement arrangements. ${ }^{3}$ A validation protocol defines how transactions are validated and included in the overall transaction history. The main objectives of the transaction history are to prevent double spending and reconcile the distributed parts of the ledger. Decentralized information could easily be copied and reused without a double-spending-prevention mechanism.

The main differences between DLT protocols are in the construction of the consensus mechanism. ${ }^{4}$ That is, how validation is done and by what kind of validators (for example, institutions, private or public entity, individuals, and so on). When there is more than one validating participant, these need to reach consensus on the transaction history. Another key difference is in the transparency of the transaction history, which affects the possibility for auditing the transaction history.

Early DLT setups were token-based and specialized for maintaining accounts of funds, but later generations enabled smart contract solutions and new applications. ${ }^{5}$ The latter can be used for maintaining different kinds of distributed registers in addition to

${ }^{2}$ See CPMI (2017). DLT refers to the processes and related technologies that enable nodes in a network (or arrangement) to securely propose, validate, and record state changes (or updates) to a synchronized ledger that is distributed across the network's nodes.

${ }^{3}$ Annex II includes a list of DLT protocols.

${ }^{4}$ See CPMI (2017) for a description of cryptographic tools and consensus mechanisms that determine how a ledger distributed across multiple nodes could have varying roles and permissions.

${ }^{5}$ Smart contract is a computer protocol that allows the programming of logic or conditionality into an asset or transaction, usually associated with DLT applications. 


\section{Box 1. The Evolving Payments System Landscape}

The key factors driving the evolution of the payments system landscape have included:

- Rapidly rising information technology processing power and storage capacity at low investment cost (for example, through cloud computing) and capacity to process big data sets, and real-time access to all systems and applications on a 24/7/365 basis, with immediate transaction-based processing. Significant advances in artificial intelligence underpin these developments.

- Greatly increased communication capacity and connectivity at very low costs directly point-to-point within networks.

- Low-cost user-interface hardware and software platforms (for example, mobile phones, personal computers, tablets, and so on) for secure interfaces and for connecting to automated devices.
- Advances in application programming interfaces between different system components across service providers resulting in modular structures of large systems.

- Enhanced common processing platforms, operative systems, open source, freeware and shareware, free libraries of apps, and widely used complex financial software applications or external software services that will facilitate the rapid development of new payment features within all kind of systems.

- Widespread use of encryption, digital identity, and e-signature services for safeguarding data and funds, recognizing business partners remotely and verifying transactions transferred over common and open telecommunication connections. accounts. For example, securities can be viewed as asset accounts of tokens or a register of smart contracts transferring ownership titles to individual shares and bonds. All proof-of-concept tests from central bank-led initiatives indicate that only permissioned DLT networks are suitable for financial market infrastructures (FMIs), considering compliance and other regulatory requirements (access, know your customer, and so on). These protocols have different features. Additionally, ongoing projects are seeking continuous improvement protocols while additional research remains to establish a stable and sustainable protocol.

\section{Experiments and Research}

Many central banks have oversight and operational responsibilities in payment and settlement systems and have taken a keen interest in DLT experiments, which provide an opportunity to test prototypes while analyzing their potential safety and efficiency implications with public interest in mind. Likewise, industry groups and participants have also used experimentations to explore market opportunities and address shortcomings in the current payments and settlement systems landscape.

\section{Large-value Payment Systems}

Prototypes confirmed the feasibility of using DLT as a transaction booking method. The proof-of-work design and the completely transparent transaction database used in Bitcoin-type protocol were deemed unsuitable for large-value payments because of processing capacity needs and lack of privacy. All prototypes were based on DLT consensus protocols using less processing resources and providing more privacy. This required more trust in the validator nodes, which is not a problem in a system maintained by the central bank or other trusted authorities.

Prototypes, however, have insufficiently focused on the necessary criteria for operational production, including throughput, ${ }^{6}$ reliability, and resiliency. Therefore, they could not be viewed as sufficient proof for production feasibility. Almost all prototypes were stand-alone type built as an add-on payment processing layer upon or in parallel with the existing LVPS. Real-time interfaces with central banks' or financial institutions' internal payment systems were not tested except for one prototype (in Singapore), which had a direct operation link with the current RTGS system.

\footnotetext{
${ }^{6}$ Throughput refers to intraday deadlines by which banks need to send a proportion of the value of their day's payments to a payment system.
} 
Privacy and liquidity savings appeared to be high priority issues for central banks. All prototypes used token-based central bank money, basically deposit receipts of the central bank. The employed system structures were based on structures supported by the selected external DLT software and protocol providers. All prototypes were block-chained with several transactions in a block. The setups were comparable to current RTGS systems and fulfilled settlement finality requirements and credit risk limitations. Regarding liquidity risks, the prototypes were dependent on the prefunded liquidity imported to the system.

Most of the experiments did not contain cost-benefit analyses. The European Central Bank and Bank of Japan reported that DLT-based systems have higher levels of reliability and resiliency compared with traditional RTGS systems, but without making any cost-benefit comparisons. The reports contained the general benefits mentioned in DLT marketing literature, like peer-to-peer communication, secured cryptography, smart contracts, immutability, and real-time settlement. However, these features can also be implemented in traditional payment systems. For example, a traditional system could also contain parallel transaction databases with parallel account balances secured by public key infrastructure (PKI) encryption and several validators.

Research and testing could consider the following:

- Implementing DLT-type solutions for reconciling and securing central bank and RTGS participants' payment transfers by using PKI-encrypted transactions and automated transaction-level reconciliation.

- A liquidity saving mechanism (LSM) based on splitting DLT payment transactions to allow for several partial settlements using readily available tokens in the correct priority order, which is not true for the liquidity saving models used in current RTGS systems. The available liquidity would be used as efficiently as possible, when even small amounts of tokens would be circulated across the network.

- Analysis of policy and operational changes needed for 24/7/365 operations with no need for end-of-day processing.

- Interoperability across different DLT implementations.

- The benefits and risks of using a universal digital asset, or basket of assets, to settle payments across borders.

- Cost and benefit analysis of different kinds of DLT implementations.

\section{Securities Settlement Systems}

DLT prototypes also showed that DLT could be viable for post-trade securities processing. All projects concluded that securities settlement is a highly suitable and feasible environment for DLT-based solutions. One of the projects (in Australia) even aimed for production implementation in 2021. Some prototypes focused on delivery-versus-payment (DvP) implementation within securities settlement systems, ${ }^{7}$ and those concluded that DvP with finality is achievable within DLT-based systems. ${ }^{8}$

The experiments showed that different DvP models can be implemented in DLT-based systems. DLT solutions can vary considerably in features and tools, with which a more efficient processing and account method can be designed and customized for improved efficiency and security in specific markets according to market needs. However, interoperability requirements will also be important in the future, which will require common elements and standards across settlement systems and across markets.

There was no conclusive analysis on which DvP transaction dialogues of the many alternatives (or combinations) would be most suitable in a production environment. The securities market has a history of large multilateral systems like exchanges, central securities depositories (CSD), settlement banks, and central counterparties (CCP) utilized by all parties. In all prototypes, the central bank was given the role of cash instrument provider and could thereby also be the one ensuring DvP requirements. One option that was tested in some of the prototypes is to create a specific DvP dialogue and blocking method for assets, which the consensus node(s) can use to ensure the DvP requirements before adding the transactions to the ledger of validated transactions. Other options included employing specialized DvP controlling nodes and splitting transactions to a chain of incremental sub-DvP transactions to reduce the principal settlement risk to that of the subtransaction size.

A project assumption appeared to be that securities clearing and settlement systems operate within a

\footnotetext{
${ }^{7} \mathrm{DvP}$ refers to a link between a securities transfer system and a funds transfer system that ensures that delivery occurs if and only if payment occurs.

${ }^{8}$ None of the projects published any detailed cost-benefit-analysis of a DLT implementation scenario, although it is expected that within the ASX project such analysis has probably been made for the strategic decision to become the first DLT production environment within securities settlement systems.
} 
market structure close to the current structure-that is, exchanges, dealers, CCPs, CSDs, custodians, and central banks operate in similar or near-similar roles as they do today and in a multilayered registration structure. None of the projects analyzed flatter market structures and DvP processing at the end-investor level or other radical structural changes in the market and associated risks. Furthermore, counterparty risks were not analyzed because the counterparties and the market structures were assumed to be identical to the current structures. Liquidity and credit risks were also not analyzed in depth and especially not for changing market structures.

Research and testing could consider the following:

- The impact of true, real-time 24/7/365 processing on system design and convention changes.

- Structural changes, especially toward flatter markets and processing conventions, that would be necessary to maximize DLT and the most efficient implementation path for such changes.

- Cost-benefit analysis of operational cost savings, security, and stability.

\section{Cross-Border Payments}

Central banks currently provide settlement services only for domestic participants. As a result, private banks developed correspondent banking services, in which cross-border settlements are executed through private banks' nostro accounts. ${ }^{9}$ Some large international banks have established subsidiaries in major markets to support their correspondent network and get access to national central bank and private systems. This situation may not change with DLT implementations, if the presumably permissioned DLT networks provided by central banks still restrict cross-border participation. A key challenge in facilitating efficient interbank cross-border settlement of large-value payments, from a technical perspective, is the lack of a common settlement platform and network providing global reach.

Central banks have explored DLT and the applicability for large-value cross-border payments:

- The Bank of Canada (BOC) and Monetary Authority of Singapore (MAS) linked their experimental domestic payment networks to enable cross-border

9In correspondent banking, nostro accounts refer to accounts held by a customer bank on the books of another bank acting as a service provider. and cross-currency payments using central bank digital currency (CBDC). ${ }^{10}$ The experiment connected two different DLT platforms that facilitated payment-versus-payment (PvP) settlement without the need for a trusted third party acting as an intermediary. ${ }^{11}$

- The BOC, MAS, and Bank of England (BOE), in an earlier study, explored alternative models for addressing shortcomings in cross-border payments. ${ }^{12}$ This included enhancing domestic interbank payment systems with current or traditional technology to using wholesale CBDC. While the new technology platforms were found to address some shortcomings, a more fundamental paradigm shift and holistic view was identified.

- Central banks believe that design considerations for wholesale digital tokens would require clarity on the nature of the claims underlying assets or funds, the legal underpinnings, and institutional and risk management. ${ }^{13}$

The banking industry has also explored the applicability of DLT for foreign exchange, messaging, and large-value payments.

- CLSNet was launched by CLS Bank International in 2018 as a DLT-based service. ${ }^{14}$ It is not a payment service but a bilateral netting service for foreign exchange trades, particularly for emerging market currencies. Associated payments are processed separately using correspondent banking relationships.

- The Society for Worldwide Interbank Financial Telecommunication (SWIFT) initiated the Global Payments Innovation (GPI) platform to improve speed, security, and transparency in payment processing standards through improved tracking and compliance monitoring. Although SWIFT GPI is not DLT-based, research is ongoing to allow blockchain companies to connect to the GPI platform, which will enable GPI payments to be initiated

\footnotetext{
${ }^{10}$ See BOC and MAS (2019).

${ }^{11} \mathrm{PvP}$ is a mechanism in a foreign exchange settlement system that ensures that a final transfer of one currency occurs if and only if a final transfer of the other currency or currencies takes place.

${ }^{12}$ See BOC, BOE, and MAS (2018).

${ }^{13}$ See CPMI (2019).

${ }^{14}$ CLSNet is a platform operated by CLS Bank International (established in 2002), which is a US-regulated financial institution that provides foreign exchange netting and settlement services through the operation of a PvP settlement service that mitigates settlement risk for foreign exchange transactions.
} 
within blockchain networks and connected to the banking system.

- JPM Coin was designed as a digital representation of a fiat currency to make instantaneous payments between J.P. Morgan's institutional clients. JPM Coin is still under development.

- Utility Settlement Coin (USC), managed by Fnality International, was designed as a digital cash settlement asset backed by a fiat currency held at the central bank and used in wholesale markets. ${ }^{15}$ USC is still under development.

International banks could probably continue to explore the possibility of establishing cross-border payment facilities through new innovations and collaboration. ${ }^{16}$ This can have far-reaching effects, including on current domestic RTGS volumes because a cross-border settlement engine can also process domestic transactions. Global banks could benefit from moving domestic transactions to a global cross-border system because liquidity pooling would be more efficient. Benefits could increase, if the reconciling and automated interfaces in the new private cross-border system are more efficient and it has longer operational hours than RTGS systems.

A common and coordinated strategy could help facilitate large-value cross-border payments. ${ }^{17}$ This could involve the financial sector, central banks, and other authorities. This should aim to rapidly achieve the benefits of advanced payment technology and DLT without facing the risks and costs related to uncoordinated developments. Large-value cross-border payments is an area in which introduction of a new global, open, and low-risk settlement solution can significantly reduce both technical and financial risks.

\section{Risk Management Issues}

New advanced technologies could also lead to evolving risks. Liquidity, credit, transaction delay, settlement

\footnotetext{
${ }^{15}$ Fnality International (Fnality) is a consortium of 15 major institutions that envisioned the creation of a tokenized settlement asset that has finality, multicurrency (US dollar, British pound, euro, Canadian dollar, and Japanese yen), and interoperability features.

${ }^{16}$ The global interbank large-value community is rather limited, with only some major banks in each country, many of which are subsidiaries of international banks operating in several countries.

${ }^{17}$ As of December 2019, the Financial Stability Board's work program for 2020 has included the development of a road map to enhance cross-border payment systems.
}

finality, counterparty, and operational risks could all change in varying degrees in a new environment, particularly because of the global interconnections within the financial markets. Like other industries, FMIs could increase their global reach. ${ }^{18}$ Payment and settlement systems could increasingly become multicurrency platforms and able to handle in parallel different kinds of currencies and other types of funds. The securities trading market could experience the largest change because of changing short selling/buying conventions.

\section{Liquidity Risks}

The movement to real-time immediate settlement could increase liquidity needs. ${ }^{19}$ However, this does not necessarily mean a need for liquidity that is higher than currently available, which, during normal days, can be forecasted based on historic transaction patterns by using simulation models built for payment and settlement systems. ${ }^{20}$ Compared to the current environment, ${ }^{21}$ the following issues could imply major changes.

- Real-time availability. Immediate real-time processing implies continuous 24/7/365 flow of liquidity without end-of-day breaks.

- Liquidity needs. Central banks would need to update their liquidity provision policies to function globally without day breaks and with automated solutions to ensure globally sufficient liquidity supply to payment and settlement system participants. Moving to immediate settlement of securities trading transactions could affect both the trading conventions and liquidity needs. ${ }^{22}$

- Flatter structures. The flatter, non-tiered, structure of DLT systems indicates that each payment and settlement system participant could oversee its own liquidity requirements, which makes the overall sys-

${ }^{18}$ Some FMIs already provide cross-border services, including CLS Bank International, Euroclear Bank, Clearstream Banking Luxembourg, TARGET2, LCH, and others.

${ }^{19}$ The upper bound of liquidity refers to the amount of liquidity that must be available to participants for immediate settlement throughout the day. Any additional liquidity above the upper bound remains idle on participants' settlement accounts for the whole day. See Leinonen and Soramäki (1999).

${ }^{20}$ The Bank of Finland's simulation model is used frequently. For details, see https://www.suomenpankki.fi/en/financial-stability/bof -pss2-simulator/.

${ }^{21}$ Traditional deferred net settlement systems have mostly operated batch-based using end-of-day settlement or faster delivery mechanisms with separate settlement periods.

${ }^{22}$ Most securities settlement systems operate on $\mathrm{T}+2$ or $\mathrm{T}+3$ basis. 
tem less dependent on individual and large clearing bank participants.

- Global connections require payment and settlement systems to become interoperable. Global DLT-based systems could reduce liquidity needs. That is, available liquidity could be pooled into one common fund to be used for all payment and settlement streams instead of a stream of specific pools.

\section{Credit Risks}

The traditional approach to managing credit risk appears to conflict with the nature of DLT. Credit risks and liquidity needs could be viewed as two sides of the same coin in payment and settlement systems. ${ }^{23}$ If a transaction has been booked on both the receiving and sending ends, then it has been settled either by using liquidity (that is, settlement funds) or by accepting credit risks of delayed interbank settlement. Credit risks could grow in a global and flat infrastructure because some banks could bilaterally have a sending surplus while others have a receiving surplus. To net such imbalances, the market would need to have a continuously operating intermediary, which could require collateral to avoid credit risks. However, this would conflict with the nature of bilateral settlement in DLT-based systems.

A more efficient solution within a real-time environment would be that settlements are only liquidity-based, and each participant ensures that sufficient liquidity is available. This could be based on central bank money but could also result in the growth of automated short-term liquidity markets (hourly or even shorter) between market participants, which could price short-term liquidity according to credit risks and other costs. Moving to a completely liquidity-based settlement would result in decreasing credit risks in payment and settlement systems.

\section{Delayed Transactions}

In RTGS systems, different kinds of LSMs are used and involve transaction queuing that implies some transaction delays. Queued transactions are settled based on different kinds of partial or complete netting algorithms. ${ }^{24}$ In a pure bilateral real-time system, the

${ }^{23}$ See Leinonen and Soramäki (1999).

${ }^{24}$ See Leinonen and Soramäki (1999). sender can delay payments or settlements only by queuing transactions internally.

If LSMs are introduced in real-time DLT-based systems, it could require a separate centralized layer for queued payments and liquidity holdings for net settlements. ${ }^{25}$ This would be possible, but it could be difficult to get acceptance for random types of payment delays depending on service providers' queuing needs. For example, an immediate payment transfer negotiated between two customers could jeopardize the business agreement between these customers if the paying bank would start to delay the corresponding payment. In an immediate securities settlement, the buyer expects to receive the securities immediately and the seller the corresponding funds. The efficiency and usability of a netting-based liquidity mechanism could depend on the possibility of queueing low-priority payments.

\section{Settlement Finality}

In a DLT-based system, transactions are updated immediately on all relevant accounts, while corrections are usually made with a new transaction. The overall transaction ledger is additive. ${ }^{26}$ Settlement finality can be clearly defined as occurred when a specific transaction is booked on both the correct sending and receiving account within a few seconds. In a real-time end-to-end system, there is no settlement window, which could generate a Herstatt-type of settlement risk. ${ }^{27}$ All successfully booked transactions are final. Old accepted blocks and transactions cannot be changed. ${ }^{28}$

\section{Counterparty Risks}

DLT implementation could result in global and flat systems. The number of counterparties in payment

\footnotetext{
${ }^{25} \mathrm{~A}$ contrary view is that DLT transactions could be technically validated if one of more nodes are inactive.

${ }^{26}$ In permissionless DLT arrangements that rely on consensus processes, the ability of participants to revise ledger transactions gives rise to probabilistic settlement because there may never be a settlement finality.

${ }^{27}$ See Galati (2002). Herstatt risk is also referred to as foreign exchange settlement risk, cross-currency settlement risk, or principal risk (CPSS 1996). It is the risk that one party to a foreign exchange transaction will pay the currency it sold but not receive the currency it bought.

${ }^{28}$ For permissioned DLT, however, most node validators or a specific node with higher rights could fork the chain from a previous block, reversing the transaction.
} 
and settlement systems could grow, and the share of cross-border transactions could increase. To reduce counterparty risks within large global payment and settlement systems, the liabilities and requirements on individual counterparties must be clear-cut and similar across the whole network of participants. By enforcing settlement in central bank money (or comparable low-risk settlement assets), counterparty risks can be reduced. However, there must also be strict rules on payment initiation and the handling of fraudulent and otherwise criminal transactions because there are always risks for different kinds of criminal activities within fund transfers.

\section{Operational Risks}

In DLT-based environments, operational and cyber risk incidents could rapidly affect many transactions. This is not different from old computerized processing, but the real-time booking environment could require very fast and highly automated error-handling processes to limit the volume of transactions affected by operational errors. This calls for improved monitoring systems and error-correction solutions. Furthermore, in Bitcoin-type DLT applications, there is no possibility to recreate lost funds. Each node in the network must technically safeguard its own funds. ${ }^{29}$ Within LVPSs and securities settlement systems, the funds at stake are so large that it could be important to recreate funds of lost nodes, especially in case of major operational risks. For example, large-scale cyberattacks could compromise data confidentiality, service availability, and systems integrity. This could also affect established settlement finality rules and recovery time objectives, which require the resumption of operations within two hours after disruptive events.

\section{Stability and Bank-Run Risk}

DLT-based systems could operate in real-time, which could accelerate bank runs. Critical banks could lose their available liquidity rapidly. If payment and settlement systems operate on credit, the credit limits of such banks could be rapidly consumed. By using artificial intelligence solutions, which are monitoring payment and settlement flows in real time, bank-run

\footnotetext{
${ }^{29}$ From a technical standpoint, nodes contain a log or ledger that is common across all nodes of a DLT system instead of actual funds.
}

situations could be detected and then stopped in early phases.

\section{Changing (Naked) Short Selling and Buying Conventions}

DLT could potentially create an environment without short selling and buying risks. DLT developments could result in custodian accounts being kept in a flat, real-time ledger. Trades could be settled immediately and automatically, directly on investor or trader accounts. In this environment, naked short selling would not be possible. The seller must ensure that the assets to be traded are available (or at least have been lent from another source). The buyer needs to have the necessary funds. This could have a major impact on current trading practices. For example, current high-frequency trading strategies are based on sending and canceling many orders, but in a true real-time environment, this would not be possible because orders would be immediately settled with finality when traded and cannot be canceled. However, after each trade and settlement, the assets can immediately be retraded according to investors' desires.

- For Delivery-versus-Delivery (DvD) transactions, the trading partners must ensure that the corresponding assets are available for immediate settlement. ${ }^{30}$ The buyer could provide securitized monetary assets like central bank certificates as payment.

- For DvP transactions, the investors or traders have to ensure that they have funds for the cash legs in their bank accounts, but this does not necessarily ensure that their clearing participant (generally their bank) would have sufficient settlement funds (for example, central bank money) for all buy trades of all their customers and investors during peak buy periods. The clearing participants need-in a real-time securities settlement environment-to improve their liquidity forecasts and enlarge their liquidity reserves if they have trading customers with highly fluctuating liquidity needs.

\section{Financial Market Infrastructure Standards}

The Committee on Payment and Settlement Systems/International Organization of Securities Com-

\footnotetext{
${ }^{30} \mathrm{DvD}$ refers to a link between two securities transfer (settlement) systems that ensures that a delivery occurs if and only if another delivery occurs and vice versa.
} 
missions (IOSCO) Principles for Financial Market Infrastructures (PFMI) serves as the international standard for assessing efficiency and risks in payment and settlement systems. Given potential DLT adoption by such infrastructures or other emerging business models in the long term, the principles could be applicable as they are technology neutral. DLT developments and discussions with authorities and market participants have started to be included as part of FMI assessments in IMF-World Bank financial sector assessment programs (Australia, Canada, Singapore, Switzerland). ${ }^{31}$

Early experiments and initial observations suggest that new interpretations could be necessary, particularly with bilateral settlements. ${ }^{32}$ DLT-based solutions could be designed as bilateral settlement transfers using a dialogue protocol without any centralized or other clearly observable physical infrastructure. Clarity on the DLT-type of structures covered (or not covered) by the PFMI could be helpful. ${ }^{33}$ Furthermore, DLT-based systems could feature different risk liability programs because the organizational setup could differ from current centralized settlement systems. In a DLT-system using token-based settlement assets, the FMI has no settlement accounts in its balance sheets. Transactions are booked in one ledger and distributed across the network where credit risk, liquidity risks, legal risk, and operational risks must be managed. Possible centralized operational services like certification authorities and transaction validation could be technical services that are separate legal entities, which are not considered FMIs.

The CPMI analytical framework for DLT-based payment, clearing, and settlement arrangements provides a basis to examine efficiency and safety implications. ${ }^{34}$ This mainly assists central banks and other authorities relative to their oversight, operational, or catalyst responsibilities, but the framework is equally useful for market participants that are considering new service offerings that could be subject to regulation, supervision, and oversight. ${ }^{35}$

\footnotetext{
${ }^{31}$ See IMF (2019b, 2019c, 2019d, 2020).

${ }^{32}$ DLT might be implemented in traditional centralized systems with multilateral net settlements, but this is a special case, in which PFMI requirements would be applied similarly as for any multilateral payment and settlement system.

${ }^{33}$ The PFMI, footnote 5, notes that the definition of FMIs excludes bilateral relationships between financial institutions and their customers, such as traditional correspondent banking.

${ }^{34}$ See CPMI (2017).

${ }^{35}$ For illustration, distributed Financial Market Infrastructures have recently been coined as a new service offering by some market participants.
}

\section{Potential Impact on the International Monetary System}

The international monetary system, which has largely operated on universal financial messaging standards, could face challenges arising from DLT. For example, many systemically important FMIs, their participants, and correspondent banks rely on SWIFT's core financial messaging services. More than 200 market infrastructures use SWIFT and about 11,000 institutions across 200 countries and territories are connected to SWIFT. ${ }^{36}$ SWIFT messaging services support domestic and international payments and facilitate the settlement of payments and securities transactions, including in central banks' monetary operations.

Interoperability issues would need to be addressed to avoid fragmentation risk. Fragmentation could arise at two levels, including: (i) interoperability of DLT systems with legacy infrastructures, and (ii) interoperability between distributed ledgers across multiple counterparties. ${ }^{37}$ In this context, the PFMI recommends the use of relevant internationally accepted communication procedures and standards to facilitate efficient payment, clearing, and settlement. Such considerations are particularly relevant for cross-border financial communications, which help identify counterparties and securities numbering processes. Where international procedures and standards are not adopted (such as standards set by the International Organization for Standardization), interoperability features should be developed to support translation or conversion between FMIs located across different jurisdictions.

\section{Conclusion}

The evolution of payment and settlement systems has reached another major crossroad with the emergence of DLT, but many important questions remain:

- When would such new technologies be mature enough to move from controlled experiments to implementation?

- Could the public policy objectives of safety and efficiency be fully observed with the replacement of legacy infrastructures with DLT-based systems or the introduction of innovative service offerings from new entrants in the market?

- What new interpretations may be needed under existing international standards?

\footnotetext{
${ }^{36}$ See IMF (2018).

${ }^{37}$ See SWIFT (2016).
} 
- What are the implications for regulation, supervision, and oversight in a world that is moving toward greater real-time settlement, flatter structures, continuous operations, and global reach?

Until we begin to answer these questions and consider the adoption of RTGS systems in most countries around the world, which has helped mitigate systemic risks and safeguard financial stability, it is not clear that DLT will gain broad traction as a basis for LVPS. 


\section{Annex I. List of DLT Experiments and Research in Payments and Settlements}

\section{Large-value Payment Systems}

- Project Jasper (Phase 1) (Canada)

- Project Jasper (Phase 2) (Canada)

- Project Khokha (South Africa)

- Project Stella (Phase 1) (Euro Area/Japan)

- Project Ubin (Phase 1) (Singapore)

- Project Ubin (Phase 2) (Singapore)

- Project Inthanon (Phase 1) (Thailand)

- Project Salt (Brazil)

\section{Securities Settlement Systems}

- Project Blockbaster (Germany)

- Project by Depository Trust and Clearing Corporation (United States)

- Project ASX replacement of CHESS (Australia)

- Project Jasper (Phase 3) (Canada)

- Project Stella (Phase 2) (Euro Area/Japan)

- Project Ubin (Phase 3) (Singapore)

- Project Inthanon (Phase 2) (Thailand)

\section{Cross-Border Payment Arrangements}

- CLSNet foreign exchange netting service (United States)

- SWIFT DLT research (Belgium)

- Utility Settlement Coin (Switzerland)

- JPM Coin (United States)

- Project Jasper (Phase 4) — Project Ubin (Phase 4) (Canada, Singapore)

- Cross-border interbank settlements (Canada, United Kingdom, Singapore)

- Project Stella (Phase 3) (Euro Area/Japan)

- Project Inthanon (Phase 3)—LionRock (Thailand, Hong Kong) 


\section{Annex II. Distributed Ledger Technology Protocols}

- Bitcoin DLT protocol was defined in 2008 (Nakamoto 2008). It was the first token-based DLT protocol. It is based on a so-called "proof-of-work" protocol used by "miners." Anonymous or pseudonymous miners compete to solve an encryption task for adding a new block to the public block-chained transaction database. Double spending is controlled by accepting only the first instance of the next transaction generated by a bitcoin node-that is, it considers that all transactions sent by a node are sequentially numbered. Because the miners in the network are unknown, it is impossible to control to what extent they collaborate, which increases the risk for so-called 51 percent abuse of mining power (Ali and Barrdear 2014). In the Bitcoin protocol, the transaction database is public. Because users' Bitcoin account addresses are pseudonymous, it is possible to identify all transactions belonging to a person once the pseudonym is revealed, for example, in connection with a transfer request.

- Digital Asset Platform is developed by the US company Digital Asset (Digital Asset 2016). It contains the Digital Asset Modeling Language for the management of contracts and contract transactions using a private contract store and a global sync log.

- Elements is a blockchain platform developed from Bitcoin that is provided by the private company Blockstream. It supports transaction confidentiality and PvP- and DvP-type cross-ledger transfers.

- Ethereum is an open-source DLT protocol for smart contracts, which is today maintained by the nonprofit organization Enterprise Ethereum Alliance.

- Hyperledger Fabric is an open-source protocol from Linux Foundation's Hyperledger Initiative that is based on smart contracts. Validation nodes validate transactions. The validating nodes are assigned validation tasks, and the other validating nodes can audit the results of other validating nodes. The validation process is thereby efficient, but users need to trust the validator nodes. All nodes, user and validation nodes, need to be recognized by a DLT network membership service. Privacy is ensured toward other nodes, but the membership service will know the identity of all other nodes.

- Quorum is an Ethereum-based enterprise-focused DLT environment for smart co,ntracts with improvements in the following areas: "network and peer permissions management, enhanced transaction and contract privacy, voting-based consensus mechanisms, and better performance," as reported by the Blockchain Council. J.P. Morgan facilitated the creation of Quorum.

- $\mathbf{R} 3 /$ Corda is an open-source protocol developed especially for the financial industry by the R3 consortium established by major international financial institutions (Brown 2018; Hearn 2016). It can run both transaction accounts and smart contracts. Unlike other DLT solutions, it has only bilateral transaction histories and therefore no common transaction database. Transactions are validated by the sending and receiving nodes and specialized notary nodes. The task of the notary node is to hinder double spending. Validation is a rapid process. Participants need to trust the notary node(s). The notary node will see all transactions and its processing speed and accuracy will affect the network. Any security problems within the notary node can jeopardize the whole network. Because of its structure, it will require different kinds of backup solutions for sufficient resiliency compared with other DLT networks.

- Sequence is protocol provided by Chain (a private US company) for managing account balances based on tokens in a ledger-as-a-service environment.

- Zilliqa is a DLT protocol employed by the Anquan Capital (public company in Singapore) blockchain platform, and it is closely related to the Elastico DLT protocol. Both use "sharding" to share mining activities among subgroups of miners, which facilitate parallel processing. This feature increases the scalability of this protocol considerably to be close to linear with increased volumes. 


\section{References}

Ali, Robleh, John Barrdear, Roger Clews, and James Southgate. 2014. "The Economics of Digital Currencies." Bank of England Quarterly Bulletin 54 (3): 276-86.

Bank of Canada and Monetary Authority of Singapore (BOC and MAS). 2019. "Jasper-Ubin Design Paper: Enabling Cross-Border High Value Transfer Using Distributed Ledger Technologies." Accenture, Dublin.

Bank of Canada, Bank of England, and Monetary Authority of Singapore (BOC, BOE, and MAS). 2018. "Cross-Border Interbank Payments and Settlements: Emerging Opportunities for Digital Transformation.” KPMG Services Pte. Ltd.

Brown, Richard Gendal. 2018. "The Corda Platform: An Introduction.” May 2018 (accessed March 2, 2019). https://www .corda.net/content/corda-platform-whitepaper.pdf.

Committee on Payment and Settlement Systems (CPSS). 1996. "Settlement Risk in Foreign Exchange Transactions." Bank for International Settlements, Basel.

Committee on Payment and Market Infrastructures (CPMI). 2017. "Distributed Ledger Technology in Payment, Clearing, and Settlement." Bank for International Settlements, Basel.

Committee on Payment and Market Infrastructures. 2019. "Wholesale Digital Tokens." Bank for International Settlements, Basel.

Digital Asset Holdings LLC. 2016. "The Digital Asset Platform: Non-technical White Paper.” December 2016 (accessed on February 9, 2019).

Galati, Gabriele. 2002. "Settlement Risk in Foreign Exchange Markets and CLS Bank.” BIS Quarterly Review (December).

Hearn, Mike. 2016. "Corda: A Distributed Ledger." November 29, 2016 (accessed on March 2, 2019).

International Monetary Fund (IMF). 2018. "Belgium Financial System Stability Assessment." Country Report No. 18/67, Washington, DC.

International Monetary Fund (IMF). 2019a. "Australia Financial Sector Assessment Program: Technical Note-Supervision, Oversight, and Resolution Planning of Financial Market Infrastructures." IMF Country Report No. 19/52, Washington, DC.
International Monetary Fund (IMF). 2019b. "Fintech: The Experience So Far.” IMF Policy Paper, June, Washington, DC.

International Monetary Fund (IMF). 2019c. "Singapore Financial Sector Assessment Program: Detailed Assessment of Observance-CPSS-IOSCO Principles for Financial Market Infrastructures." IMF Country Report No. 19/255, Washington, DC.

International Monetary Fund (IMF). 2019d. "Switzerland Financial Sector Assessment Program: Technical NoteSupervision and Oversight of Financial Market Infrastructures.” IMF Country Report No. 19/190, Washington, DC.

International Monetary Fund (IMF). 2020. "Canada Financial Sector Assessment Program: Technical Note-Oversight of Financial Market Infrastructures and Fintech Development." IMF Country Report No. 20/22, Washington, DC.

Leinonen, Harry, and Kimmo Soramäki. 1999. "Optimizing Liquidity Usage and Settlement Speed in Payment Systems.” Bank of Finland Discussion Papers 16/1999, Helsinki.

Nakamoto, Satoshi. 2008. "Bitcoin: A Peer-to-Peer Electronic Cash System.” (Accessed February 4, 2019).

Society for Worldwide Interbank Financial Telecommunication (SWIFT). 2016. "SWIFT on Distributed Ledger Technologies: Delivering an Industry Standard Platform through Community Collaboration." SWIFT SCRL, La Hulpe, Belgium. 


\section{DISTRIBUTED}

\section{LEDGER TECHNOLOGY}

\section{EXPERIMENTS IN PAYMENTS}

\section{AND SETTLEMENTS}

PART 1

Distributed Ledger Technology

PART 2

Experiments and Research

PART 3

Risk Management Issues

PART 4

Financial Market Standards

PART 5

Potential Impact on the

International Monetary System

\section{PUBLICATIONS}

Distributed Ledger Technology Experiments in Payments and Settlements 